\title{
Blood pressure and salt intake in Malawi: an urban rural study
}

\author{
D SIMMONS*, G BARBOUR, J CONGLETON, J LEVY, P MEACHER, \\ H SAUL, AND T SOWERBY
}

From The Anglo Malawi Hypertension Survey 1983

SUMmaRY A significant difference between the blood pressures of rural and urban Malawians was found in both sexes, was present at the age of 15 years, and was associated with obesity but not with smoking, alcohol consumption, occupation or housing. Pulse rate was significantly lower in the urban group. These differences were accompanied by low potassium and sodium intake although the sodium intake in the urban group was double that in the rural group. No direct relation between blood pressure and urinary electrolytes was found.

Malawi is located in central Africa and has a population of over six million, most of whom are African in origin. The country is divided into three regions: north, south, and central, the latter containing the new capital of Lilongwe (population 600 000). This city has been expanding in both population and size over the last 25 years, and to accommodate the influx well demarcated housing estates have been built. Because of the rapid increase in size of Lilongwe, nearby villages have remained relatively unchanged by the growth of the city. This close proximity of urban and rural groups provided an opportunity to study the blood pressure distribution in Malawians in the two settings.

No previous blood pressure survey in Malawi has been reported, although a large number of surveys have been conducted in other Southern and East African nations. ${ }^{1-8}$ The purpose of this survey was to describe and compare blood pressures in urban and rural Malawians and to investigate the relation to age, anthropometric measurements, and urinary electrolyte excretion.

\section{Subjects}

The urban sample was selected from the first building estate established in Lilongwe in 1962: the Falls Estate. It was thought that this would be most likely to have a more "normal" age distribution. The population came from all over Malawi with representatives of all the tribes. Water was piped directly to houses which were

*Correspondence to: Flat 32D, Phase III, Walsgrave Hospital, Coventry CV2 2DX brick, two to three roomed bungalows arranged in $\frac{0}{0}$ ? rows. The men were mainly white collar workers with $\underset{\mathbb{\infty}}{\stackrel{\infty}{\infty}}$ some manual workers.

The villages of Gunde and Msinje are situated $22 \stackrel{\varnothing}{\circ}$ 을 miles south west of Lilongwe and are linked by road $\vec{\sigma}$ and rough track. They were chosen by the Health $\varnothing \subsetneq$ Service as "typical" of rural villages, although they음 were larger than most to allow an adequate number of $\overrightarrow{0} \cdot \overrightarrow{0}$ subjects for this study. The inhabitants were born? almost exclusively in the central region. Water was collected from a central pump, and huts were chiefly of wood and mud. The men were mainly farmers.

Both groups ate "Nsima" made from the staple diet of African maize. This was usually eaten with a relish of meat, fish or vegetables.

All the inhabitants aged 15 and over were identified by means of a house to house survey until a sample of over 500 urban and 500 rural Malawians was enumerated. Any blocks or outlying hamlets that had been started were included in their entirety. This was cross checked with lists of household members made during the blood pressure survey itself.

\section{Method}

Seven university students (six medical) were trained ${ }^{9}$ to use the Hawkesley random zero sphygmomanometer ${ }^{10}$ by the Medical Research Council Hypertension Trials training officer. Before the survey, an observer comparison was made with 12 subjects, and no statistically significant difference between observers was detected. It was also ensured during the survey that comparable numbers in each 10 year age sex group were seen by each observer. 
The procedure used was fully standardised. ${ }^{11}$ The subject sat in his own home with the back to a wall and legs out straight supported by the wall or furniture. The left elbow rested on a custom built arm rest, ensuring that the blood pressure cuff would be at the level of the heart. Surrounding clothing was removed. For oversized arms, large cuffs were used. During a timed 10 minute rest period, the observer completed a questionnaire on age, name, date of birth, marital status, number in household, number over 18 years, number of rooms, occupation, education, district of birth and of parents' birth, length of time in current and past residences, smoking and drinking habits, how often salt was added to the food, and current medication. Age was assessed in the rural sample with questions on village history.

Two successive measurements of systolic and diastolic blood pressure were taken, and the true blood pressures were taken as the mean of the two values. If there was a difference in systolic blood pressure of 20 $\mathrm{mmHg}$ or more, or $10 \mathrm{mmHg}$ more in diastolic blood pressure, the recording was repeated up to twice more and the closest values were used.

After the recording had been taken, anthropometric measurements, pulse (beats/min), standing height (m), weight $(\mathrm{kg})$, and arm circumference $(\mathrm{cm})$, were made using standardised procedures. ${ }^{12}$ Body mass was computed using the body mass index, weight/height ${ }^{2}$.

Urine samples were requested from men allotted even subject numbers, and the first specimen passed in the morning was collected. In addition, every tenth man (by subject number) was given a bottle to fill over a 24 hour period. A $25 \mathrm{ml}$ aliquot was taken from each urine sample and brought back to England for analysis. Sodium and potassium contents were assessed by flame photometry and creatinine by the Jaffe method.

Statistics were computed using the Fortran based package Genstat ${ }^{13}$ on the Cambridge IBM 3801 computer. Individuals with a diastolic blood pressure above $105 \mathrm{mmHg}$ were referred for treatment.

\section{Results}

An overall response rate of $96.9 \%$ was obtained, 1008 of the 1040 inhabitants participating in the survey. Of the urban sample, 270 of the 281 men $(96.1 \%)$ and 239 of the 245 women $(97.6 \%)$ were seen; and of the rural sample, 207 of the 218 men (95.0\%) and 292 of the 296 women $(98.6 \%)$ were seen.

No significant difference in parameters such as blood pressure, age, pulse rate, arm circumference, and body mass index was found between villages constituting the rural group. Region of birth (an indicator of tribal background) was also found to have no significant effect.

\section{BLOOD PRESSURE-ANTHROPOMETRIC AND} SOCIAL MEASUREMENTS

Table 1 and figs 1 and 2 illustrate the relation between blood pressure and age by sex and residency.

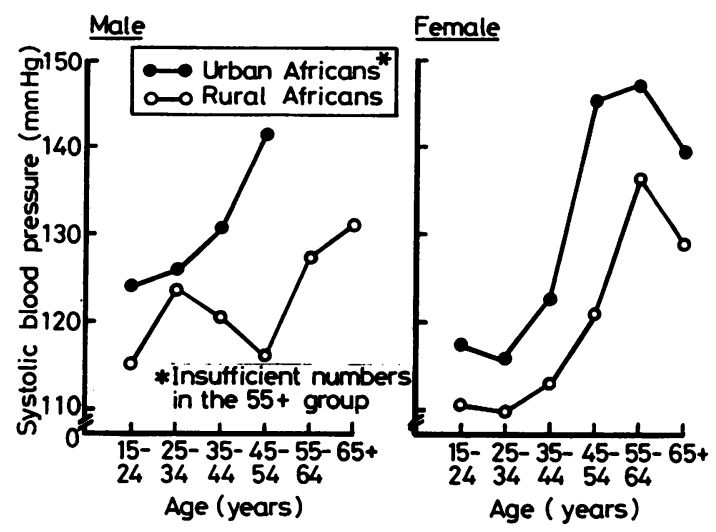

Fig 1 Systolic blood pressure by 10 year age groups

Table 1 Systolic and diastolic blood pressures by sex and age in urban and rural areas: mean (SD)

\begin{tabular}{|c|c|c|c|c|c|c|c|}
\hline \multirow{2}{*}{\multicolumn{2}{|c|}{ Age (yr) }} & \multicolumn{3}{|c|}{ Males } & \multicolumn{3}{|c|}{ Females } \\
\hline & & $N$ & $S B P(m m H g)$ & $D B P(m m H g)$ & $\boldsymbol{N}$ & $S B P(m m H g)$ & $D B P(m m H g)$ \\
\hline $15-24$ & $\begin{array}{l}\mathbf{R} \\
\mathbf{U}\end{array}$ & 72 & $114.74 \pm 14.06$ & $58.01 \pm 14 \cdot 14$ & 80 & $110.63 \pm 13.02$ & $62.85 \pm 11.74$ \\
\hline \multirow{2}{*}{$25-34$} & $\mathbf{R}$ & 37 & $\begin{array}{l}123.97 \pm 13.55 \\
123.77 \pm 16.24\end{array}$ & $\begin{array}{l}68.37 \pm 14 \cdot 14 \\
71 \cdot 04 \pm 11.57\end{array}$ & $\begin{array}{r}103 \\
71\end{array}$ & $\begin{array}{l}117.34 \pm 12 \cdot 12 \\
109.61 \pm 11.87\end{array}$ & $\begin{array}{l}71 \cdot 60 \pm 12 \cdot 27 \\
64.63 \pm 11 \cdot 22\end{array}$ \\
\hline & $\mathbf{U}$ & 70 & $125.75 \pm 15.71$ & $77.81 \pm 11.88$ & 87 & $115.64 \pm 16.20$ & $74 \cdot 71 \pm 12 \cdot 80$ \\
\hline \multirow[t]{2}{*}{$35-44$} & $\mathbf{R}$ & 39 & $120.42 \pm 16.31$ & $73 \cdot 72 \pm 10 \cdot 15$ & 57 & $112.75 \pm 15.00$ & $67.98 \pm 9.05$ \\
\hline & U & 64 & $130 \cdot 27 \pm 18.31$ & $83.66 \pm 13.49$ & 36 & $122.53 \pm 17.41$ & $75 \cdot 19 \pm 11 \cdot 39$ \\
\hline \multirow[t]{2}{*}{$45-54$} & $\mathbf{R}$ & 22 & $116 \cdot 25 \pm 12 \cdot 27$ & $67.25 \pm 9.79$ & 43 & $120 \cdot 77 \pm 24 \cdot 10$ & $69.81 \pm 9.95$ \\
\hline & U & 20 & $141 \cdot 27 \pm 27.62$ & $87.27 \pm 18.94$ & 5 & $145 \cdot 20 \pm 12 \cdot 32$ & $76.20 \pm 6.91$ \\
\hline \multirow{2}{*}{$55-64$} & $\mathbf{R}$ & 19 & $127 \cdot 18 \pm 15 \cdot 57$ & $68.92 \pm 9.82$ & 19 & $136.61 \pm 20.87$ & $68.61 \pm 7.55$ \\
\hline & $\mathbf{U}$ & 3 & $124.83 \pm 4.31$ & $77.33 \pm 7.09$ & 3 & $147 \cdot 17 \pm 37 \cdot 05$ & $75.83 \pm 7.42$ \\
\hline \multirow[t]{2}{*}{$65+$} & $\mathbf{R}$ & 18 & $131 \cdot 19 \pm 25 \cdot 96$ & $65.97 \pm 12.67$ & 22 & $128 \cdot 64 \pm 20 \cdot 30$ & $67.36 \pm 9.49$ \\
\hline & $\mathbf{U}$ & 2 & $168.25 \pm 3.89$ & $103.25 \pm 7.42$ & 5 & $139.40 \pm 8.82$ & $79.80 \pm 10.18$ \\
\hline
\end{tabular}


D Simmons, G Barbour, J Congleton, J Levy, P Meacher, $H$ Saul, and T Sowerby

190

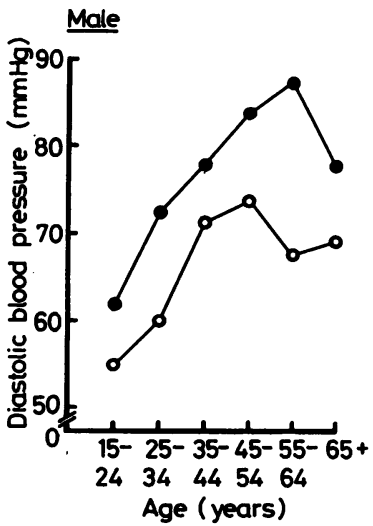

Female

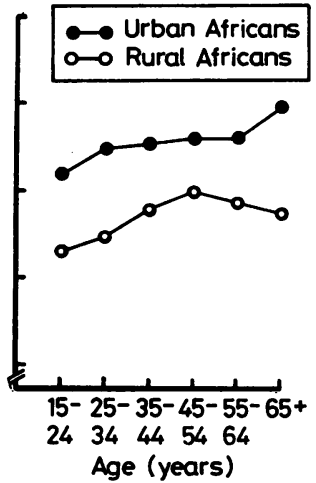

Fig 2 Diastolic blood pressure by 10 year age groups

Table 2 shows anthropometric and blood pressure measurements. Urban dwellers were significantly larger in all ways $(p<0.001)$ and had higher blood pressures $(p<0.05-0.001)$. However, the pulse rate was significantly lower (men $p<0.001$, women $\mathrm{p}<0.05$ ). After adjustment for differences in age between the urban and rural men and women, using an analysis of covariance, statistically significant differences in both systolic and diastolic blood pressure remain (table 3). The urban dwellers lived in more crowded houses with 3.29 inhabitants per room compared with 2.73 per room for the rural dwellers $(p<0.001)$. They had also had more rooms per dwelling to live in (urban 2.29, rural 1.24; $p<0.0001$ ). However, analysis of variance showed no effect on blood pressure for either.

Most of the rural men were farmers $(67 \cdot 1 \%)$ or white collar workers $(21.2 \%)$. Of the urban men $71.5 \%$ were white collar workers, the rest being mainly manual workers, and the latter tending to live more in estates elsewhere, mainly in Lilongwe. Of the urban women $43.5 \%$ were white collar workers, and almost all the rest were housewives; $80.8 \%$ of rural women were housewives. Only 11 rural men had been to high school (5.3\%) and none had had higher education. In comparison, $42.2 \%$ of urban men had been to high school and $22.2 \%$ had had higher eudcation. Under half of urban women $(42.3 \%)$ and $1.3 \%$ of rural women had been to high school or had higher education. Occupation, educational level, and smoking and drinking habits all had no demonstrable effect on blood pressure.

The number of years lived in the city was difficult to assess. Men were found to migrate to work and then to return to their own village later in life.

\section{URINARY ELECTROLYTES}

No statistically significant difference was found in blood pressure, weight, age, pulse, body mass index or
Table 2 Mean and standard deviation of systolic and diastolic blood pressures, pulse rate, age, weight, body mass index (BMI = weight/height ${ }^{2}$ ) and arm circumference, by sex, in rural and urban areas.

\begin{tabular}{|c|c|c|c|c|c|c|c|}
\hline \multirow[b]{3}{*}{$\begin{array}{l}\text { Systolic BP } \\
\text { (mmHg) }\end{array}$} & \multicolumn{3}{|c|}{ Rural } & \multicolumn{2}{|l|}{ Urban } & \multirow{2}{*}{\multicolumn{2}{|c|}{ F Value }} \\
\hline & Sex & Mean & $S D$ & Mean & $S D$ & & \\
\hline & $\begin{array}{l}\mathbf{F} \\
\mathbf{M}\end{array}$ & $\begin{array}{l}115 \cdot 34 \\
120 \cdot 16\end{array}$ & $\begin{array}{l}18 \cdot 07 \\
16 \cdot 88\end{array}$ & $\begin{array}{l}118.92 \\
127 \cdot 54\end{array}$ & $\begin{array}{l}16 \cdot 06 \\
17 \cdot 47\end{array}$ & $\begin{array}{r}5.72 \\
21 \cdot 57\end{array}$ & 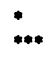 \\
\hline $\begin{array}{l}\text { Diastolic BP } \\
(\mathbf{m m}(\mathbf{H g})\end{array}$ & $\begin{array}{l}\mathbf{F} \\
\mathbf{M}\end{array}$ & $\begin{array}{l}66.02 \\
65.97\end{array}$ & $\begin{array}{l}10.70 \\
13.49\end{array}$ & $\begin{array}{l}73 \cdot 57 \\
76 \cdot 20\end{array}$ & $\begin{array}{l}12 \cdot 22 \\
15 \cdot 50\end{array}$ & $\begin{array}{l}57.84 \\
57.00\end{array}$ & $* * *$ \\
\hline $\begin{array}{l}\text { Pulse rate } \\
\text { (beats/min) }\end{array}$ & $\begin{array}{l}\mathbf{F} \\
\mathbf{M}\end{array}$ & $\begin{array}{l}83 \cdot 29 \\
77 \cdot 91\end{array}$ & $\begin{array}{l}12 \cdot 77 \\
15 \cdot 68\end{array}$ & $\begin{array}{l}80 \cdot 99 \\
73 \cdot 36\end{array}$ & $\begin{array}{l}11 \cdot 33 \\
12 \cdot 05\end{array}$ & $\begin{array}{r}4 \cdot 73 \\
12 \cdot 87\end{array}$ & $*$ \\
\hline Age & $\begin{array}{l}\mathbf{F} \\
\mathbf{M}\end{array}$ & $\begin{array}{l}36 \cdot 53 \\
36 \cdot 63\end{array}$ & $\begin{array}{l}16 \cdot 48 \\
17 \cdot 26\end{array}$ & $\begin{array}{l}28 \cdot 01 \\
29 \cdot 74\end{array}$ & $\begin{array}{l}11 \cdot 00 \\
10 \cdot 59\end{array}$ & $\begin{array}{l}46.76 \\
28.91\end{array}$ & $* * *$ \\
\hline Weight (kg) & $\begin{array}{l}\mathbf{F} \\
\mathbf{M}\end{array}$ & $\begin{array}{l}54 \cdot 02 \\
56 \cdot 12\end{array}$ & $\begin{array}{l}6.84 \\
7.68\end{array}$ & $\begin{array}{l}58 \cdot 63 \\
60 \cdot 76\end{array}$ & $\begin{array}{l}11 \cdot 06 \\
10 \cdot 16\end{array}$ & $\begin{array}{l}34 \cdot 60 \\
30 \cdot 12\end{array}$ & $* * *$ \\
\hline BMI $\left(\mathrm{kg} / \mathrm{m}^{2}\right)$ & $\begin{array}{l}\mathbf{F} \\
\mathbf{M}\end{array}$ & $\begin{array}{l}0.22 \\
0.21\end{array}$ & $\begin{array}{l}0.03 \\
0.02\end{array}$ & $\begin{array}{l}0.24 \\
0.22\end{array}$ & $\begin{array}{l}0.05 \\
0.03\end{array}$ & $\begin{array}{l}24.49 \\
16.53\end{array}$ & $* * *$ \\
\hline $\begin{array}{l}\text { Arm circumference } \\
\text { (cm) }\end{array}$ & $\begin{array}{l}\mathbf{F} \\
\mathbf{M}\end{array}$ & $\begin{array}{l}26 \cdot 61 \\
25 \cdot 23\end{array}$ & $\begin{array}{l}2.24 \\
2 \cdot 69\end{array}$ & $\begin{array}{l}27 \cdot 66 \\
26 \cdot 58\end{array}$ & $\begin{array}{l}3.61 \\
2.75\end{array}$ & $\begin{array}{l}16.76 \\
28.98\end{array}$ & $* * *$ \\
\hline
\end{tabular}

$\mathrm{p}<0.05$

$\mathrm{p}<0.001 * *$

Table 3 Age adjusted systolic and diastolic blood pressure sex, in urban and rural areas

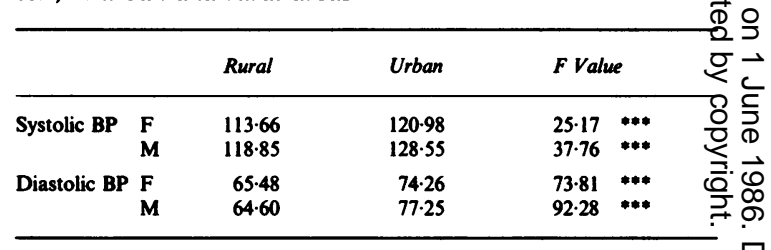

$p<0.001 * * *$

circumference between those who gave urine samples and those who did not.

Overnight samples (table 4)

Response rates of $87.9 \%$ (123 out of 140 ) in the urban sample and $71.6 \%$ (78 out of 109$)$ in the rural sample were obtained.

A difference in urinary sodium concentration between urban and rural groups was found $(p<0.001)$ in a ratio of almost $2: 1$ respectively. The $\mathrm{Na}$ /creatinine ratio was higher in the urban group $(p<0.001)$. There was no significant difference in potassium excretion, and hence the difference in $\mathrm{Na} / \mathrm{K}$ ratio $(\mathrm{p}<0.001)$ is due entirely to the difference in sodium excretion. Creatinine output was greater in the urban group $(p<0.001)$ even when weight was taken into account $(p<0.05)$. Overnight urinary volumes were low but not significantly different.

Twenty four hour samples

Response rates of $67.9 \%$ (19 out of 28 ) in the urban 
Table 4 Overnight urinary excretion parameters

\begin{tabular}{|c|c|c|c|c|c|c|}
\hline & \multicolumn{2}{|l|}{ Rural } & \multicolumn{2}{|l|}{ Urban } & \multirow[b]{2}{*}{$F$ value } & \\
\hline & Mean & $S D$ & Mean & $S D$ & & \\
\hline No. of samples & & 78 & & 123 & & \\
\hline $\begin{array}{l}\mathrm{Na}(\mathrm{mmol} / \mathrm{l}) \\
\mathrm{K}(\mathrm{mmol} / \mathrm{l}) \\
\text { Creat. (mmol/l) }\end{array}$ & $\begin{array}{r}52.507 \\
25.200 \\
9114.078\end{array}$ & $\begin{array}{r}29.573 \\
17.439 \\
4320.445\end{array}$ & $\begin{array}{r}94.726 \\
29.681 \\
11242.656\end{array}$ & $\begin{array}{r}62 \cdot 806 \\
21 \cdot 536 \\
5835 \cdot 910\end{array}$ & $\begin{array}{r}31 \cdot 232 \\
2.394 \\
7.694\end{array}$ & $\begin{array}{l}3^{*} \\
\text { NS } \\
3^{*}\end{array}$ \\
\hline Vol (ml) & 275.610 & $185 \cdot 187$ & $297 \cdot 140$ & 213.961 & 0.537 & NS \\
\hline $\mathrm{Na} / \mathrm{K}$ & 2.717 & 1.773 & 3.827 & $2 \cdot 470$ & $12 \cdot 154$ & $3 *$ \\
\hline $\mathrm{Na}$ /creat. & 6.773 & 4.479 & 9.608 & $7 \cdot 187$ & 9.812 & $3^{*}$ \\
\hline K/creat. & 3.061 & $2 \cdot 142$ & 2.793 & 1.788 & 0.910 & NS \\
\hline
\end{tabular}

$p<0.05 * p<0.012 * p<0.0013^{*}$

sample and $63.6 \%$ (14 out of 22$)$ in the rural sample were obtained.

Concentrations of electrolytes and $\mathrm{Na}$ /creatinine ratios were not significantly different from those in overnight collections, and the volumes produced were roughly in proportion to overnight sample volumes. Only the 24 hour sodium output was significantly different (rural $37 \cdot 46+31 \cdot 10 \mathrm{mmol} / 24 \mathrm{~h}$; urban $71.81+42.42 \mathrm{mmol} / 24 \mathrm{~h}: \mathrm{p}<0.05)$.

\section{LOCAL CONDIMENTS}

Rural inhabitants were found to add homemade condiments to their food. Amounts were small, and because of increasing use of manufactured salt this habit is on the decline. Samples were taken of wood ash and maize cob ash, and both were high in potassium salts (wood ash $143 \mathrm{mmol} / 1$, maize cob ash $280 \mathrm{mmol} / 1$ ) and low in sodium salts (wood ash $<1$ mmol, maize cob ash $3 \mathrm{mmol} / 1$ ).

\section{Discussion}

The very high response rate $(98.2 \%$ of women and $95.6 \%$ of men) achieved suggests that the results are representative of the parameters of this population. Surprisingly, response rates were slightly higher in the male urban sample than in the male rural sample.

After taking age into account, urban dwellers had consistently higher mean systolic and diastolic blood pressures. In other African urban rural comparisons, this difference has also been found, ${ }^{314} 15$ but generally not before the age of $\mathbf{4 0}$ years. In this study, a significant difference was found even in the 15-24 years age group, indicating that either genetic factors (for example, self selection) are involved or environmental factors which affect blood pressure rapidly or before the age of 15 years. A rapid increase in blood pressure with change in environment was shown in Samburu warriors in Kenya after only 26 months. ${ }^{16}$

In both urban and rural men, blood pressure increased with age. The difference between age groups was generally greater in the urban dwellers. In view of the probable slight genetic differences (unless they are a self selecting group) an environmental cause for the high blood pressure is likely. Differences in sodium consumption have been implicated in other studies, ${ }^{18}$ and appropriate dietary differences have been found in Malawi.

These dietary differences between rural and urban groups are necessitated by the essentially cash economy of town dwellers and the subsistence economy of villagers. The availability of salt would obviously be greater for the town dwellers, and this is shown by the differences between the two groups in urinary sodium excretion. It is interesting to note that there is no significant difference in urinary potassium excretion between the two groups. The amounts of various foods eaten were also different, as shown by the higher weights and body mass index in town dwellers-unless heavier and larger people migrate selectively to towns.

As expected, the urinary sampling had a lower response rate than the overall response rate; subjects often forgot to give a sample, especially those in the village. However, individuals who gave samples were similar to those who did not. There was no difference in urinary volume collected between rural and urban dwellers. The differences in creatinine were more likely to be due to differences in weight rather than incomplete collection of urinary samples. Low urinary volumes compared to those of other studies ${ }^{14}$ is suggest that the samples were incomplete. Decomposition of creatinine may also have had an effect.

Sodium output in the urban sample was twice that in the rural sample even though potassium output was the same. Age had no effect. In fact, compared to other African groups, ${ }^{14}{ }^{15}$ both urinary electrolytes are low, as are the $\mathrm{Na} / \mathrm{K}$ urinary excretion ratios, although this is not a "no salt population".

No relation between electrolytes and blood pressure could be shown directly, but this is typical of surveys of this kind. ${ }^{19}{ }^{20} \mathrm{~A}$ contemporary view is that somehow potassium lowers blood pressure and sodium raises it, ${ }^{21}$ but not if the potassium intake is low. ${ }^{22}$ Hence if the urban rural blood pressure differences are due mainly to electrolyte intakes, it is the sodium that has been the most important.

The existence of a high potassium condiment is of interest in view of the hunt for a salt alternative, ${ }^{23}$ although it is probably added minimally in view of the low potassium output. It may be that salt has only recently been added to food instead of the ash solutions, and hence the older rural inhabitants have had a relatively sodium free diet in the past, resulting in lower blood pressure.

Stress is often cited to be a cause of hypertension, ${ }^{17}$ but one would expect a raised blood pressure to be 
associated with a raised heart rate. In this study, however, the pulse rate was greater in the rural group, suggesting that sympathetic stimulation does not contribute significantly to the difference in blood pressure between these rural and urban populations unless the rural groups were more intimidated by the investigation and actually have an even lower blood pressure.

Naturally, whether these results are representative of Malawians as a whole is difficult to assess. Although the rural sample is both likely to be and said by local health officers to be "typical", the urban sample is unlikely to be so. Although the Falls Estate is the second oldest estate in Lilongwe (over 20 years old), the population is in constant flux. Generally, once Malawians have no work to do in Lilongwe they return to their villages.

There are other factors that complicate rural urban comparison. Although the villagers will on the whole come from a similar background, town dwellers are more cosmopolitan, coming in this study from all three regions of Malawi. This almost certainly implies tribal and hence genetic differences between the urban and rural dwellers. In spite of this, no significant differences in any parameters could be found between subjects from the three regions. Hence it is assumed that the urban sample can be grouped as one for analysis. However, due to the relatively small number studied, differences between the three groups might have been missed. The unavailability of lighting prevented evening visits in the village, and the " 9 till 5 " working routine for men in the town prevented a visit during the day, except at lunchtime. This might bias the results due to diurnal rhythms and variation in ambient temperature, which could affect blood pressure through heat losing mechanisms such as sweating and vasodilatation.

The rural men were mostly farmers while the urban men were white or blue collar workers. No significant difference in blood pressure was found between urban occupational groups.

In spite of differences in types of dwelling and crowding between the rural site and the Falls Estate, these had no effect on blood pressure.

\section{References}

1 Truswell AS, Kenelly BM, Hansen JDL, Lee RB. Blood pressure of Ikung Bushmen in Northern Botswana. Am Heart $J$ 1972; 84: 5-12.
${ }^{2}$ Mann GV, Shaffer RD, Anderson RS, Sandstead HN. Cardiovascular diseases in the Masai. $J$ Atherosclerosis Res 1964 4: 289-312.

${ }^{3}$ Scotch NA. A preliminary report on the relation of sociocultural factors to hypertension among the Zulu. Ann NY Acad Sci 1960 84: 1000-9.

${ }^{4}$ Shaper AG, Wright DM, Kyobe J. Blood pressure and body build in 3 nomadic tribes of Northern Kenya. $E$ Afr Med J 1969 46: 273-81.

${ }^{5}$ Williams AW. Blood pressure differences in Kikuya and Samburu communities in Kenya. E Afr Med J 1969 46: 262-72.

${ }^{6}$ Shaper AG, Saxton GA. Blood pressure and body build in a rural community in Uganda. $E$ Afr Med $J 1981$ 46: 228-45.

${ }^{7}$ Wwapa FK. Blood pressure distribution in 2 rural Zambian communites. In: Zambia and Cardiovascular Disease 1983 48-52.

8 Vaughan JP. Blood pressure and heart murmurs in a rural population in the United Republic of Tanzania. Bull WHO 1979 57: 89-97.

${ }^{9}$ Rose G. Standardisation in blood pressure measurement. Lancet 1965 i: 673-4.

10 Wright, BM, Dore F. A random zero sphygmomanometer. Lancet 1970 i: $337-8$.

11 Simmons D. Blood pressure, ethnic group and salt intake in Belize. J Epidemiol Community Health 1983 37: 38-42.

12 Rose G, Blackburn H. Cardiovascular survey methods. Geneva: World Health Organisation 1968 (Monograph Series).

${ }^{13}$ Lawes Agricultural Trust (Rothamstead Experimental Station) GENSTAT 1984.

14 Sever PS, Gordon D, Peart WS, Beighton P. Blood pressure and its correlates in urban and tribal Africa. Lancet 1980 ii: $60-4$.

15 Poulter N, Khaw KT, Hopwood BEC, Mugambi M, Peart 8 WS, Rose G, Sever PS. Blood pressure and its correlates in an African tribe in urban and rural environments. Epidemiol Community Health 1984 38: 181-6.

16 Shaper AG, Leonard PJ, Jones KW, Jones M. Environmental effects on the body build, blood pressure, and blood chemistry of nomadic warriors serving in the army in Kenya. E Afr Med J 1969 46: 282-9.

${ }^{17}$ Graham J DP. High blood pressure after battle. Lancet 1945 i: $239-40$.

18 Gleiberman L. Blood pressure and dietary salt in human populations. Ecology of food and nutrition 1973 2: 143-56.

19 Miall WE. Follow up study of arterial pressure in the population of a Welsh mining valley. Br Med J 1959 2: $1204-10$.

${ }^{20}$ Watt GCM, Foy CJW. Dietary sodium and arterial pressure: problems of studies within a single population. $J$ Epidemiol Community Health 1982 36: 197-201.

21 Meneely GR, Batterbec MD. High sodium, low potassium environment and hypertension. Am J Cardiol 1976 38: 768-85.

22 Smith SJ, Markandu ND, Sagnella GA, MacGregor GA. Moderate potassium supplementation in essential hypertension. Is it additive to moderate salt restriction? Br Med J (Clin Res) 1985 290: 6462 110-3.

${ }^{23}$ MacGregor GA, Smith SJ, Markandu ND, Banks RA, Sagrella GA. Moderate potassium supplementation in essential hypertension. Lancet 1982 ii: 567-70. 